\title{
Drug resistance, serotypes, and phylogenetic groups among uropathogenic Escherichia coli including 025-ST131 in Mexico City
}

\author{
José Molina-López ${ }^{1,2}$, Gerardo Aparicio-Ozores ${ }^{1}$, Rosa María Ribas-Aparicio ${ }^{1}$, Sandra \\ Gavilanes-Parra ${ }^{2}$, María E. Chávez-Berrocal ${ }^{2}$, Rigoberto Hernández-Castro ${ }^{3}$, H. Ángel \\ Manjarrez-Hernández ${ }^{2}$
}

${ }^{1}$ Departamento de Microbiología de la Escuela Nacional de Ciencias Biológicas (IPN), Prolongación de Carpio

y Plan de Ayala s/n, México, D.F. 11340, México

${ }^{2}$ Departamento de Salud Pública, Facultad de Medicina, UNAM, México DF, 04510, México

${ }^{3}$ Dirección de Investigación, Hospital General Dr. Gea González, Tlalpan, DF, 14080, México

\begin{abstract}
Introduction: The increasing prevalence of uropathogenic Escherichia coli (UPEC) strains resistant to multiple antibiotics complicates the treatment of urinary tract infections (UTIs). This study aimed to analyze the antimicrobial resistance, serotypes, and phylogenetic groups among strains of $E$. coli isolated from outpatients with UTIs in Mexico City.

Methodology: A total of $119 \mathrm{E}$. coli isolates were recovered from urine samples from outpatients with clinical diagnosis of uncomplicated UTIs from 2004 to 2007. The serotype was assessed by agglutination in microtiter plates; susceptibility to antimicrobials was determined by the disk diffusion method. Clone O25-ST131 and phylogenetic groups of E. coli strains were tested by methods based on PCR multiplex.

Results: The predominant serotype was O25:H4 (21.2\%). Resistance to antibiotics was ampicillin (83.7\%); piperacillin (53.8\%); the fluoroquinolone group (55.5-60.6\%), and trimethoprim/sulfamethoxazole (TMP/SMX) (56.4\%). Additionally, 36 (30.2\%) isolates were multidrug-resistant and 13 of these 36 strains were identified as E. coli O25-ST131 clone by an allele-specific PCR-based assay. Phylogenetic analysis showed that 15 of 17 isolates with serotype $\mathrm{O} 25: \mathrm{H} 4$ belonged to group B2.

Conclusions: This is the first report that establishes the presence in Mexico of the O25-ST131 clonal group of E. coli, which has been associated with multidrug-resistance and with high virulence potential. The spread of this clone in Mexico should be monitored closely. We found a correlation between serotype O25:H4 and multidrug resistance in UPEC strains. Our results indicate that the use of ampicillin, fluoroquinolones, and TMP/SMX should be reviewed when selecting empirical therapy for UTIs.
\end{abstract}

Key words: urinary infection; uropathogenic Escherichia coli; O25-ST131; multidrug-resistance

J Infect Dev Ctries 2011; 5(12):840-849.

(Received 29 October 2010 - Accepted 05 June 2011)

Copyright (C) 2011 Molina-López et al. This is an open-access article distributed under the Creative Commons Attribution License, which permits unrestricted use, distribution, and reproduction in any medium, provided the original work is properly cited.

\section{Introduction}

The uropathogenic Escherichia coli (UPEC) strains are responsible for the majority of urinary tract infections (UTIs) [1,2] that occur in $70-90 \%$ of the seven million cases of acute cystitis and 250,000 cases of pyelonephritis reported annually in the United States $[2,3]$. The incidence of UTI is greater in women as compared to men, and approximately half of all women have had a UTI by their late 20s [4]. These organisms are responsible for significant social and economic costs for both communities and public health resources [5].

In almost all UTI cases, empirical antimicrobial treatment is initiated before the laboratory results of the urine culture are available. However, to optimize the use of empirical antibiotic therapy for UTIs, it is important for clinicians to be aware of the susceptibility patterns of UPEC strains in their specific geographical locations or populations [6]. The clinical management of UTI is complicated by the increasing incidence of infections caused by strains of $E$. coli that are resistant to commonly used antimicrobial agents [7]. In recent years, there has been an increase in the occurrence of strains of $E$. coli causing UTIs that are resistant to cephalosporins, fluoroquinolones, and trimethoprim, which has special clinical importance because of the limited therapeutic options available [8].

Urinary tract infection is not usually thought of as a disease associated with community-wide outbreaks; certain multidrug-resistant uropathogenic lineages of E. coli have exhibited epidemic behaviour [9]. In 
Table 1. Serogroups identified in UPEC strains obtained from 119 outpatients who were diagnosed in one of three hospitals

\begin{tabular}{|c|c|c|c|}
\hline Serogroups & \multicolumn{3}{|c|}{ Hospital origin } \\
\hline O25 & $\mathrm{GG}^{1}$ & $\mathrm{GM}^{2}$ & $\mathrm{GC}^{3}$ \\
\hline $\mathrm{O} 6$ & 3 & 9 & 5 \\
\hline O8 & 2 & 0 & 3 \\
\hline O1 & 3 & 1 & 1 \\
\hline O2 & 1 & 1 & 1 \\
\hline O4 & 3 & 0 & 1 \\
\hline O75 & 1 & 1 & 1 \\
\hline O86 $^{2}$ & 1 & 1 & 1 \\
\hline O101 $^{2}$ & 1 & 1 & 1 \\
\hline O102 $^{2}$ & 0 & 2 & 2 \\
\hline OR $^{4}$ & 3 & 1 & 0 \\
\hline ONT $^{5}$ & 6 & 4 & 7 \\
\hline Others $^{\text {Total }}$ & 11 & 4 & 12 \\
\hline
\end{tabular}

${ }^{1} \mathrm{GG}=$ Gea Gonzalez Hospital

${ }^{2} \mathrm{GM}=$ General Hospital of Mexico

${ }^{3} \mathrm{GC}=$ Gonzalo Castañeda Hospital

${ }^{4} \mathrm{OR}=$ Rough somatic antigen

${ }^{5} \mathrm{ONT}=$ Non-typable somatic antigen

1986-1987, E. coli O15:K52:H1 caused an outbreak of community-acquired UTIs and septicaemia in South London, UK [10]. The distinctive drug resistance profile of this clonal group contributed to its recognition in London and other areas of Europe and the United States [11].

E. coli strains can be characterized by their antimicrobial drug susceptibility profile, serotyping, and phylogenetic typing in four groups: A; B1; B2, and D) $[9,12]$. The majority of strains responsible for extraintestinal infections, including UTI, belong to group B2 or, to a lesser degree, to group D, whereas commensal isolates belong to groups $\mathrm{A}$ and $\mathrm{B} 1$ $[13,14]$.There is no comprehensive surveillance for community-acquired UTIs in Mexico City; therefore, it is very difficult to estimate the true incidence of UTIs and to monitor the spread of these organisms. Thus it is necessary to analyze serological and phylogenetic characteristics of UPEC strains recovered from a Mexican population. Recently, an $E$. coli clone, O25-ST131, has emerged worldwide as important cause of community-onset UTI $[15,16]$. This clone with high virulence potential produces extended spectrum beta-lactamase (ESBL) enzymes and is frequently multidrug-resistant [17]. We do not know if this E. coli clone has spread to Mexico. In addition, the prevalence of antimicrobial resistance in UPEC strains is an increasing concern in Mexico because there is growing resistance to the drugs of choice: ampicillin; cotrimoxazole, and ciprofloxacin. Furthermore, approximately $10 \%$ of isolates were resistant to ceftazidime, and three-fourths of these produced ESBLs $[18,19]$. In Mexico, the overall rate of antibiotic resistance is high, more so than in other comparable countries. Indeed, the prevalence of resistance appears higher than that of developed countries, and even than that observed in other Latin American countries [20]. There are few available options to treat UTIs in the community. Here we report the result of a study that assessed antimicrobial resistance and its relationship with serotypes and phylogenetic groups among $E$. coli isolates from outpatients with UTIs in Mexico City.

\section{Methodology}

Source of bacterial strains and selection criteria

A total of $119 \mathrm{E}$. coli clinical isolates were obtained from urine samples from the same number of outpatients with uncomplicated UTIs. Samples were obtained from three Mexico City based hospitals: the Dr. Gonzalo Castañeda Escobar General Hospital (ISSSTE, Institute for Social and Health Services for Government Employees), Hospital Gea Gonzalez (Ssa, Ministry of Health), and the Hospital General de Mexico (Ssa) (Table 1). The strains studied are representative of Mexico City: the first hospital is located in the north of the city; the second in the south, and the third in downtown Mexico City. Urinary samples of adult outpatients between the ages of 17 and 70 years suffering from uncomplicated urinary infection were collected between 2004 and 2007. Of the 119 isolates, $82(68.9 \%)$ were from women and 37 (31\%), from men. A case of E. coli UTI was defined as that accompanied by symptoms suggestive of infection and a culture of a clean-catch urine specimen with at least $10^{5}$ colony forming units of E. coli per millilitre (CFUs/mL) [21]. Patients were excluded if they met one of the following criteria: if they were pregnant; if they had diabetes, if they were immunocompromised; or if other suspected sources of infection were present.

Isolation was performed according to standard laboratory protocols [22]. The urine sample was collected aseptically, spread onto blood agar, and biochemical identification of E. coli species was 
determined by the Vitek Automated System 32 (BioMérieux, Marcy l'Etoile, France). Strains biochemically confirmed as $E$. coli were maintained in Luria Bertani (LB) broth with $15 \%$ glycerol at $-20^{\circ} \mathrm{C}$.

\section{Serotyping}

The strains were serotyped by agglutination assays [23] using 96-well microtiter plates and rabbit serum (SERUNAM) obtained against 185 somatic antigens (O) and 53 flagellar antigens $(\mathrm{H})$ for E. coli, and against 45 somatic antigens for Shigella species. Rabbit serum against $E$. coli strain 64474:H32 was also prepared [24]. In addition, serotyping of the $E$. coli strains was confirmed with 186 anti-O E. coli and 45 anti-O Shigella sera from the Laboratory of Gastrointestinal Pathogens, Health Protection Agency, London, UK [25].

\section{Antimicrobial susceptibility testing}

Twenty antimicrobial agents were tested by the disk diffusion method in accordance with the Clinical and Laboratory Standards Institute [26]: $30 \mu \mathrm{g} / \mathrm{mL}$ Amikacin (AN); $30 \mu \mathrm{g} / \mathrm{mL}$ Amoxycillin/clavulanic acid (AMC); $30 \mu \mathrm{g} / \mathrm{mL}$ Cephazolin (CZ); $30 \mu \mathrm{g} / \mathrm{mL}$ Cefepime (FEP); $30 \mu \mathrm{g} / \mathrm{mL}$ Ceftazidime (TAZ); 30 $\mu \mathrm{g} / \mathrm{mL}$ Ceftriaxone (CTR); $30 \mu \mathrm{g} / \mathrm{mL}$ Cefuroxime (ROX); $5 \mu \mathrm{g} / \mathrm{mL}$ Ciprofloxacin (CIP); $10 \mu \mathrm{g} / \mathrm{mL}$ Gentamicin (GM); $10 \mu \mathrm{g} / \mathrm{mL}$ Meropenem (MEM); $300 \mu \mathrm{g} / \mathrm{mL}$ Nitrofurantoin (FD); $10 \mu \mathrm{g} / \mathrm{mL}$ Norfloxacin (NOR), $5 \mu \mathrm{g} / \mathrm{mL}$ Ofloxacin (OFX); 100 $\mu \mathrm{g} / \mathrm{mL} \quad$ Piperacillin (PIP); $7.5 / 85 \quad \mu \mathrm{g} / \mathrm{mL}$ Ticarcillin/clavulanic acid (TCC); 25/475 $\mu \mathrm{g} / \mathrm{mL}$ Trimethoprim/sulfametoxazole (TMP/SMX); 10 $\mu \mathrm{g} / \mathrm{mL}$ Ampicillin (AMP); $100 \mu \mathrm{g} / \mathrm{mL}$ Carbenicillin (CAR); $30 \mu \mathrm{g} / \mathrm{mL}$ Nalidixic acid (NA), and $10 \mu \mathrm{g} / \mathrm{mL}$ Tobramicin (TOB) (antimicrobial susceptibility disks, Oxoid. UK). The results were interpreted as described [24]. E. coli ATTC 25922 and Pseudomonas aeruginosa ATCC 27853 were used as controls. Multidrug resistance was defined as resistance to three or more different classes of antibiotics.

\section{Phylogenetic analysis}

Phylogenetic groups were determined by triplex PCR assay [13], using a combination of three DNA markers $(c h u \mathrm{~A}, \quad y j a \mathrm{~A}$ and the DNA fragment TSPE4.C). PCR was performed in a $20 \mu \mathrm{L}$ volume containing $2 \mu \mathrm{L}$ of $10 \mathrm{x}$ buffer, $1.5 \mathrm{mM} \mathrm{MgCl}_{2}, 30$ pmol of each primer (Accesolab, Mexico), $2 \mu \mathrm{M}$ of each dNTP, $1 \mathrm{U}$ of Taq polymerase (Fermentas, Glen Burnie, MA, USA) and $2 \mu \mathrm{L}$ of extracted DNA (InstaGene Matrix, Bio-Rad, Hercules, CA, USA).
PCR was performed with a GeneAmp PCR System 9700 (Applied Biosystems, Shanghai, China) under the following conditions: denaturalization for 5 minutes at $95^{\circ} \mathrm{C} ; 30$ cycles of 30 seconds at $94^{\circ} \mathrm{C} ; 30$ seconds at $55^{\circ} \mathrm{C} ; 30$ seconds at $72^{\circ} \mathrm{C}$, and a final extension of 7 minutes at $72^{\circ} \mathrm{C}$. PCR products were loaded on $1.5 \%$ agarose gels and stained with ethidium bromide $0.5 \mu \mathrm{g} / \mathrm{mL}$. After electrophoresis, the gel was photographed under ultraviolet (UV) light in a gel documentation system (BioSens SC 645, Shanghai, China). The obtained combination of PCR products allowed us to classify the $E$. coli isolates into one of the four major $E$. coli phylogenetic lineages: A; B1; $\mathrm{B} 2$, and D.

\section{PCR detection of O25-ST131 clone isolates}

Only isolates with serogroups $\mathrm{O} 25$ were tested to determine whether they belonged to the O25-ST131 clone by utilizing a PCR-based assay (allele-specific PCR for the pabB gene) according the method described by Clermont et al. [27]. For this, PCR was carried out in a $20 \mu \mathrm{L}$ volume containing $2 \mu \mathrm{L}$ of $10 \mathrm{x}$ buffer, $1.5 \mathrm{mM} \mathrm{MgCl} 2,30$ pmol of each primer, $2 \mu \mathrm{M}$ of each dNTP, $1 \mathrm{U}$ of Taq polymerase (Fermentas, Glen Burnie, MA, USA), and $2 \mu \mathrm{L}$ of extracted DNA (InstaGene Matrix, Bio-Rad). PCR was performed with an GeneAmp PCR System 9700 (Applied Biosystems) under the following conditions: denaturalization for 4 minutes at $94^{\circ} \mathrm{C} ; 30$ cycles for 5 seconds at $94^{\circ} \mathrm{C}$, and 10 seconds at $65^{\circ} \mathrm{C}$, and a final 5 minute extension step at $72^{\circ} \mathrm{C}$. PCR products were loaded on $1.5 \%$ agarose gel and stained with ethidium bromide $0.5 \mu \mathrm{g} / \mathrm{mL}$ (Bio-Rad). After electrophoresis, gel was photographed under UV light in a gel documentation system (BioSens SC 645).

\section{Statistical analyses}

For statistical analysis, we used the chi-square test to compare the frequency among the four phylogenetic groups and multi-drug resistant strains, using SPSS statistical software version 15.0 (IBM, Chicago, USA).

\section{Results}

Serotyping

Serotyping of the 119 studied strains revealed that they belong to diverse serogroups. Eighty (67.2\%) were O-antigen typeable, $22(25 \%)$ were non-typeable because they did not react with any of the 186 antisera used, and $17(21.2 \%)$ were rough because they reacted non-specifically. Sixty (50.4\%) of the 119 strains examined were $\mathrm{H}$-antigen typeable, 56 (47.0\%) were motile (M) although they were negative to the $\mathrm{H}$ - 
Table 2. Prevalence of antibiotic resistance among 119 UPEC isolates

\begin{tabular}{|l|c|c|}
\hline \multirow{2}{*}{ Antibiotics } & \multicolumn{2}{|c|}{ Resistance } \\
\cline { 2 - 3 } & No. & $\%$ \\
\hline Ampicillin & 98 & 83.7 \\
\hline Carbenicillin & 74 & 63.2 \\
\hline Ofloxacin & 71 & 60.6 \\
\hline Norfloxacin & 71 & 60.6 \\
\hline Nalidixic acid & 66 & 56.4 \\
\hline Trimethoprim/sulfamethoxazole & 66 & 56.4 \\
\hline Ciprofloxacin & 65 & 55.5 \\
\hline Piperacillin & 63 & 53.8 \\
\hline Tobramicin & 36 & 30.7 \\
\hline Ticarcillin/clavulanic acid & 30 & 25.6 \\
\hline Gentamicin & 28 & 23.9 \\
\hline Cefazolin & 24 & 20.5 \\
\hline Amoxicillin/clavulanic acid & 23 & 19.6 \\
\hline Cefuroxime & 17 & 14.5 \\
\hline Ceftriazone & 12 & 10.2 \\
\hline Ceftazidime & 10 & 8.5 \\
\hline Cefepime & 7 & 7.6 \\
\hline Nitrofurantoin & 5.1 \\
\hline Amikacin & 1 & 0.85 \\
\hline Meropenem & 7.7 \\
\hline
\end{tabular}

antigen serological test, and three $(2.5 \%)$ were nonmotile (NM), because they did not possess the $\mathrm{H}$ antigen. Thus the O-typeable strains were distributed into 31 serogroups and 29 serotypes. Forty of the 80 typeable strains belonged to serogroups $\mathrm{O} 1, \mathrm{O} 2, \mathrm{O} 4$, $\mathrm{O} 6, \mathrm{O} 8, \mathrm{O} 25$, and $\mathrm{O} 75$, which were previously reported for UPEC. Among the 29 identified serotypes, the following were the most frequent: $\mathrm{O} 25: \mathrm{H} 4$ with 17 isolates (21.2\%), and O8:NM and O6:H1 with 5 each $(6.2 \%$ each) (Table 1). Twenty isolates presented serogroups O11, O77, O86, O101, O102, and O166, which were different from the commonly encountered UPEC serogroups.

\section{Antimicrobial susceptibilities}

The 119 studied uropathogenic strains from Mexico City expressed highest resistance rates to the following: ampicillin, 98 isolates (83.7\%); carbenicillin, 74 (63.2\%); norfloxacin, 71 (60.6\%); ofloxacin, $71 \quad(60.6 \%) ; \quad$ trimethoprim / sulfamethoxazole, 66 (56.4\%); and ciprofloxacin, 65 $(55.5 \%)$. The lowest percentage of resistance was for meropenem, 1 (0.85\%); amikacin, 2 (1.7\%); nitrofurantoin, $6(5.1 \%)$; cefepime, 9 (7.6\%); ceftazidime, $10(8.5 \%)$; and ceftriaxone, 12 (10.2\%) (Table 2). Thirty-six (30.2\%) isolates were resistant to at least three classes of the following tested antimicrobial agents: penicillins and penicillins plus clavulanic acid; fluoroquinolones; trimethoprim / sulfamethoxazole; aminoglycosides, and cephalosporins, and were designated as multi-drug resistant (MDR). Patterns of multi-drug resistance are shown in Table 3. A pattern of resistance to three different families of antibiotics (penicillins, fluoroquinolones, and trimethoprim / sulfamethoxazole) was found in 13 of the 17 serotypes $\mathrm{O} 25: \mathrm{H} 4$ isolates; this involves resistance to eight different antibiotics. Two of these $\mathrm{O} 25: \mathrm{H} 4$ isolates were resistant to five different families of antibiotics (Table 3).

\section{Phylogenetic group analysis}

E. coli isolates could also be assigned to four phylogenetic groups, namely, A, B1, B2, and D. Our analysis showed that $43(36 \%)$ of the studied isolates belonged to group B2, 34 (28.7\%) to A, 32 (27.8\%) to $\mathrm{D}$, and $10(8.4 \%)$ to group B1. Fourteen strains of serogroup $\mathrm{O} 25: \mathrm{H} 4$ were assigned to group $\mathrm{B} 2$, two to group $\mathrm{D}$, and one to group A (Table 4).

Subsequently, we examined the association between MDR and the phylogenetic group. A statistically significant correlation between MDR and the B2 phylogenetic group was found. On the other hand, there was no statistically significant correlation between MDR or non-MDR strains and the A, B1, or D groups (Table 4).

\section{Detection of the O25-ST131 clone}

Thirteen of 17 isolates of serogroup O25 were identified as belonging to the O25-ST131 clone utilizing an allele-specific PCR-based assay for the $p a b B$ gene of this clone (Figure 1). Ten of these isolates also corresponded to the B2 phylogenetic group. It is noteworthy that three of the isolates belonging to the O25-ST131 clone corresponded to phylogenetic groups D and A. 
Table 3. Distribution of serotypes and phylogenetic groups in the 36 multidrug resistant (MDR) UPEC isolates

\begin{tabular}{|c|c|c|c|c|c|c|c|c|c|c|c|c|c|c|c|c|c|c|c|}
\hline \multirow{2}{*}{$\begin{array}{c}\begin{array}{c}\text { Hospital } \\
\text { origin }\end{array} \\
\text { 1-GM } \\
\end{array}$} & \multirow{2}{*}{$\begin{array}{l}\text { Serotype } \\
\text { O25:H4 } \\
\end{array}$} & \multirow{2}{*}{$\begin{array}{c}\text { Phylo- } \\
\text { genetic } \\
\text { group } \\
\mathrm{A}^{*}\end{array}$} & \multicolumn{3}{|c|}{ Penicillins } & \multicolumn{2}{|c|}{$\begin{array}{c}\text { Penicillin } \\
\text { plus } \\
\text { betalacta- } \\
\text { mase } \\
\text { inhibitors }\end{array}$} & \multicolumn{5}{|c|}{ Cephalosporines } & \multicolumn{2}{|c|}{$\begin{array}{l}\text { Aminogly } \\
\text {-cosides }\end{array}$} & \multicolumn{4}{|c|}{$\begin{array}{l}\text { Quinolones } \\
\text { and } \\
\text { fluoro- } \\
\text { quinolones }\end{array}$} & \multirow{2}{*}{$\begin{array}{l}\text { TMP/SMX } \\
\text { TMP/SMX } \\
\end{array}$} \\
\hline & & & AMP & & PIP & & & & & & & & & & NA & & NOR & OFX & \\
\hline $2-G^{1}$ & $\mathrm{O} 25: \mathrm{H} 4$ & $\mathrm{~B} 2 *$ & AMP & CAR & & & & CTR & & ROX & FEP & TAZ & GM & & NA & CIP & NOR & OFX & TMP/SMX \\
\hline $3-\mathrm{GM}^{2}$ & $\mathrm{O} 25: \mathrm{H} 4$ & B2* & AMP & CAR & PIP & & & CTR & & ROX & FEP & TAZ & & & NA & CIP & NOR & OFX & \\
\hline 4-GC & $\mathrm{O} 25: \mathrm{H} 4$ & $\mathrm{~B} 2 *$ & AMP & CAR & PIP & & & CTR & & & & & & & NA & CIP & NOR & OFX & TMP/SMX \\
\hline 5-GG & $\mathrm{O} 25: \mathrm{H} 4$ & $\mathrm{~B} 2 *$ & AMP & CAR & & AMC & & & & & & & & TOB & NA & CIP & NOR & OFX & TMP/SMX \\
\hline 6-GM & $\mathrm{O} 25: \mathrm{H} 4$ & $\mathrm{~B} 2 *$ & AMP & & & & & & & & & & GM & & & CIP & NOR & OFX & TMP/SMX \\
\hline $7-\mathrm{GG}^{3}$ & O25:H4 & $\mathrm{B} 2 *$ & AMP & CAR & PIP & AMC & TCC & & $\mathrm{CZ}$ & & & & & & NA & CIP & NOR & OFX & TMP/SMX \\
\hline 8-GG & $\mathrm{O} 25: \mathrm{H} 4$ & $\mathrm{~B} 2 *$ & AMP & CAR & & & & & & & & & & TOB & NA & CIP & NOR & OFX & TMP/SMX \\
\hline 9-GM & $\mathrm{O} 25: \mathrm{H} 4$ & $\mathrm{~B} 2 *$ & AMP & CAR & PIP & & & & & & & & & & NA & CIP & NOR & OFX & TMP/SMX \\
\hline $10-\mathrm{GC}$ & $\mathrm{O} 25: \mathrm{H} 4$ & $\mathrm{~B} 2 *$ & AMP & CAR & PIP & & & & & & & & & & NA & CIP & NOR & OFX & \\
\hline 11-GC & $\mathrm{O} 25: \mathrm{NM}^{4}$ & B2* & AMP & CAR & & & & & & & & & GM & TOB & NA & CIP & NOR & OFX & TMP/SMX \\
\hline 12-GC & $\mathrm{O} 25: \mathrm{H} 4$ & B2 & AMP & CAR & PIP & & & CTR & $\mathrm{CZ}$ & ROX & FEP & & & TOB & NA & CIP & & OFX & \\
\hline 13-GM & $\mathrm{O} 25: \mathrm{H} 4$ & B2 & AMP & CAR & PIP & & & & & & & & GM & & NA & CIP & NOR & OFX & TMP/SMX \\
\hline 14-GM & $\mathrm{O} 25: \mathrm{H} 4$ & B2 & AMP & CAR & & & & & & & & & GM & TOB & NA & CIP & NOR & OFX & TMP/SMX \\
\hline 15-GM & $\mathrm{O} 25: \mathrm{H} 4$ & $\mathrm{~B} 2$ & AMP & CAR & PIP & & & & & & & & GM & TOB & NA & CIP & NOR & OFX & TMP/SMX \\
\hline 16-GM & $\mathrm{O} 25: \mathrm{H} 4$ & $\mathrm{D}^{*}$ & AMP & CAR & PIP & & & & & & & & & & NA & & NOR & OFX & TMP/SMX \\
\hline 17-GM & $\mathrm{O} 25: \mathrm{H} 4$ & $\mathrm{D}^{*}$ & AMP & CAR & & & & & & & & & & & NA & CIP & NOR & OFX & TMP/SMX \\
\hline 18-GG & O6:H1 & B2 & AMP & CAR & PIP & AMC & TCC & & $\mathrm{CZ}$ & & & & & & & & & & TMP/SMX \\
\hline 19-GC & O6:H1 & $\mathrm{B} 2$ & AMP & CAR & PIP & & TCC & & & & & & & TOB & NA & & & & TMP/SMX \\
\hline 20-GG & O8:NM & $\mathrm{B} 2$ & AMP & CAR & PIP & AMC & & & $\mathrm{CZ}$ & ROX & & TAZ & GM & & NA & CIP & NOR & OFX & TMP/SMX \\
\hline 21-GC & O8:NM & A & AMP & CAR & PIP & & TCC & & & & & & & & NA & CIP & NOR & OFX & TMP/SMX \\
\hline 22-GG & O86:H8 & A & AMP & & PIP & AMC & TCC & & $\mathrm{CZ}$ & & & & & & NA & & & OFX & TMP/SMX \\
\hline 23-GM & O86:NM & $\mathrm{D}$ & AMP & CAR & & & & & & ROX & & & & & NA & & & & \\
\hline 24-GM & O100:H12 & A & AMP & CAR & PIP & & & & & & & & GM & & NA & CIP & NOR & OFX & TMP/SMX \\
\hline 25-GM & O100:H31 & B1 & AMP & CAR & PIP & & & CTR & & ROX & FEP & TAZ & & TOB & NA & CIP & NOR & OFX & TMP/SMX \\
\hline 26-GM & O101:NM & A & AMP & CAR & PIP & & & & & & & & & TOB & & & & & TMP/SMX \\
\hline 27-GM & O101:NM & A & AMP & CAR & PIP & & TCC & & & & & & & TOB & NA & CIP & & OFX & TMP/SMX \\
\hline 28-GM & O101:NM & $\mathrm{B} 2$ & AMP & CAR & & & TCC & & & & & & & TOB & & & & & TMP/SMX \\
\hline 29-GG & O102:H18 & $\mathrm{B} 2$ & AMP & & PIP & $\mathrm{AMC}$ & & & & ROX & & & GM & TOB & NA & CIP & NOR & OFX & \\
\hline 30-GG & O102:H6 & D & AMP & & PIP & AMC & & & & & & & & & NA & CIP & NOR & & TMP/SMX \\
\hline 31-GC & ONT:NM & A & AMP & CAR & & & TCC & & & & & & GM & TOB & NA & CIP & NOR & OFX & \\
\hline 32-GM & ONT:NM & A & AMP & CAR & & & & & & & & & GM & & & CIP & NOR & OFX & \\
\hline 33-GG & ONT:NM & B1 & AMP & CAR & PIP & AMC & TCC & CTR & $\mathrm{CZ}$ & & FEP & TAZ & GM & & & CIP & NOR & OFX & \\
\hline 34-GG & ONT:H6 & $\mathrm{D}$ & AMP & & PIP & AMC & TCC & & & ROX & & & & & & CIP & NOR & OFX & \\
\hline $35-\mathrm{GC}$ & OR:NM & A & AMP & CAR & PIP & & & & $\mathrm{CZ}$ & & & & & & & CIP & & & TMP/SMX \\
\hline 36-GG & OR:NM & $\mathrm{D}$ & AMP & & PIP & $\mathrm{AMC}$ & TCC & & & & & & & TOB & & CIP & NOR & OFX & TMP/SMX \\
\hline
\end{tabular}

AMP: Ampicillin; CAR: Carbenicillin; PIP: Piperacillin; AMC: Amoxicillin/clavulanate; TCC: Ticarcillin/clavulanic acid; CTR: Ceftriaxone; CZ: Cefazolin; ROX: Cefuroxime; FEP: Cefepime; TAZ: Ceftazidime; MEM: Meropenem; GM: Gentamicin; TOB: Tobramicin; NA: Nalidixic acid; CIP: Cirprofloxacin; NOR: Norfloxacin; OFX: Ofloxacin; TMP/SMX: Trimethoprim/ sulfamethoxazole. ${ }^{1} \mathrm{GC}=$ Gonzalo Castañeda Hospital. ${ }^{2} \mathrm{GM}=$ General Hospital of Mexico. ${ }^{3} \mathrm{GG}=$ Gea Gonzalez Hospital. $4 \mathrm{NM}=$ Non motile. ${ }^{*}$ Positives to O25-ST131 
Figure 1. PCR detection of Escherichia coli O25b-ST131 clone. The trpA (427bp) corresponds to the positive control amplifying in all isolates, whereas the $p a b B$ band $(347 \mathrm{bp})$ corresponds to the allele-specific amplification obtained only for the O25b-ST131 clone strains. M, molecular weight marker, 100 bp DNA ladder; lanes 1-17, strains: 2-GC, 3-GM, 4-GC, 12-GC, 13-GM, 14-GM, 1-GM, 5-GG, 6GM, 15-GM, 7-GG, 8-GG, 9-GM, 10-GC, 11-GC, 16-GM, 17GM

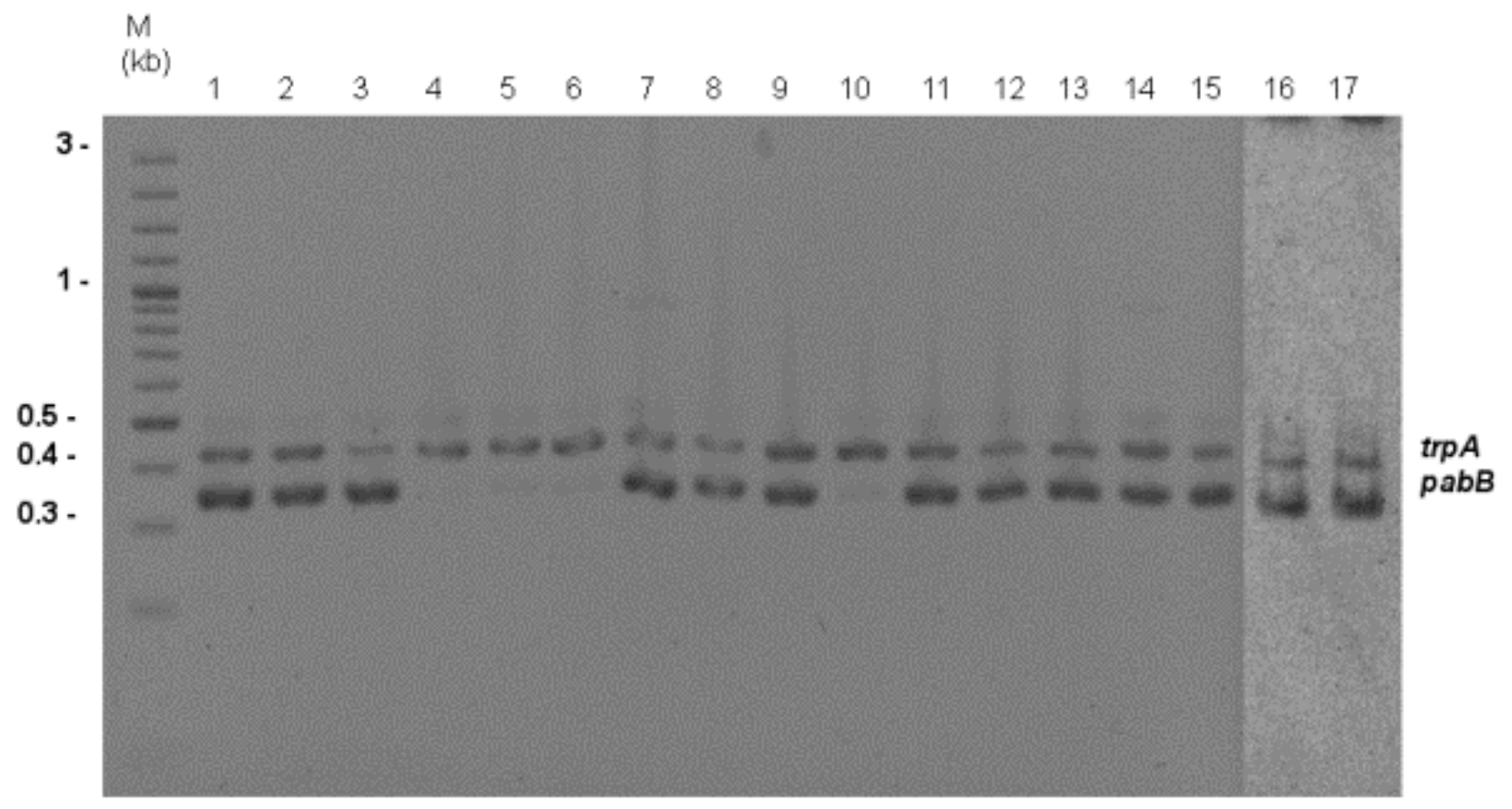

\section{Discussion}

Our findings provide evidence of multidrugresistant strains of $E$. coli that caused communityacquired UTI in patients in Mexico City, including some E. coli isolates of the clone O25-ST131. This clone has recently been shown to be disseminated worldwide and there was a significant association between $\mathrm{O} 25$ serogroups and designated sequence type 131 (ST-131) [15, 28]. In our study, 10 of the 17 isolates serotyped as $\mathrm{O} 25$ were found positive with a PCR-based assay that identifies the O25-ST131 clone with high likelihood of producing ESBLs, including CTX-M-15. These isolates, such as clone O25-ST131, belonged to the phylogenetic group B2 and all were multidrug-resistant (MDR). Although we did not identify these isolates by multilocus sequence typing (MLST), we have strong evidence that these 10 isolates belong to the O25-ST131 clone, indicating that this clone has spread to Mexico City. It has been reported that most of the O25-ST131 isolates are multidrug-resistant and commonly produce CTX-M15 ESBL enzymes [16], causing UTI and significant morbidity and mortality; this clone constitutes a major public health concern [16,27,28]. Molecular epidemiological studies suggested that the sudden worldwide increase of CTX-M-15 producing E. coli was mainly due to a single clone (ST131) and that foreign travel to high-risk areas, such as the Indian subcontinent, might in part play a role in the spread of this clone across different continents [29]. It is generally accepted that the capacity of UPEC to cause disease among humans varies according to the presence and type of virulence factors within each lineage [30]. The existence of a predominant sequence type, ST-131, among antibiotic-resistant clinical isolates of $E$. coli suggests that this genetic lineage may have acquired virulence determinants that enable it to cause UTIs.

Uropathogenic E. coli strains usually belonged to a limited number of O serogroups, mainly O1, O2, O6 O18, and 075 [31]. However, in this study, the most frequent was $\mathrm{O} 25: \mathrm{H} 4$ (21.2\%) (Table 1), which is well-established as associated with UTIs. We must emphasize that the urine samples were taken from ambulatory patients and from three different hospitals, in accordance with our statistical design for obtaining a representative sample. Among UPEC strains, serogroup $\mathrm{O} 25$ has traditionally not been recognized as prevalent worldwide. Serogroups O6 and O2 have 
Table 4. Multidrug resistance (MDR) and non-MDR of phylogenetic groups in UPEC isolates

\begin{tabular}{|c|c|c|c|}
\hline $\begin{array}{c}\text { Phylogenetic } \\
\text { group }\end{array}$ & \multicolumn{2}{|c|}{ Prevalence, no. (\%) } & \\
\hline & MDR n $=36$ & non-MDR n $=30$ & $P$ value* \\
\hline A & $9(25)$ & $11(36.6)$ & $\mathbf{0 . 1 1}$ \\
\hline B1 & $2(5.5)$ & $3(10)$ & $\mathbf{0 . 0 6}$ \\
\hline B2 & $19(52.7)$ & $7(23.3)$ & 0.03 \\
\hline D & $6(16.6)$ & $9(30)$ & $\mathbf{0 . 1 0}$ \\
\hline
\end{tabular}

commonly been the most prevalent in previous studies of UTIs.

Historically, E. coli serogroup O25 formed part of Enterotoxigenic E. coli (also known as ETEC), and ETEC is not considered to be part of extraintestinal pathogenic E. coli (ExPEC) [32]. It does not seem that serogroup $\mathrm{O} 25$ was ever a major enterotoxigenic clone, although some clonal groups have been identified among ETEC strains [33]. This O25 serogroup has been among the most prevalent ETEC serogroups recovered from patients with travellers' diarrhoea in Mexico [34]. Whether O25 ETEC strains are related to urinary tract infections remains to be elucidated. Nevertheless, in this study no other serogroup was found with higher frequency than $\mathrm{O} 25$ ETEC, which may suggest its importance and relation to urinary tract infections.

Picard et al. note that carboxylesterase type B2 UPEC strains (which correspond to the E. coli phylogenetic group B2) were more susceptible to antibiotics than carboxylesterase type B1 strains (which correspond to phylogenetic groups A, B1, and D) [35]. Other studies on E. coli from human isolates confirmed the negative association between resistances and virulence factors [36,37] with high inferred virulence among strains of the B2 phylogenetic group. Our investigation revealed that $52.7 \%$ (19 of 36) of our MDR isolates belonged to virulent phylogenetic group B2 (Tables 2 and 4), there were a statistically significant correlation between MDR and the B2 group (Table 4), suggesting that antimicrobial resistance could be compatible with certain strains that carry virulence-factor genes, such as the successful pathogen O25-ST131 clone.

In this study, the large majority $(82.3 \%)$ of $\mathrm{O} 25: \mathrm{H} 4$ isolates were assigned to the virulent extraintestinal phylogenetic group B2. Recently, ST131, O25:H4, and phylogenetic group B2 were shown as the major clones (88\%) among CTXM-15producing E. coli isolates in Europe, Asia, and North America [15]. Furthermore, ST131 strains have been associated with ciprofloxacin resistance in Europe [38] and were isolated from the stools of healthy individuals in France [39]. These reports also document the spread and success of the ST131 E. coli lineage. Phylogenetic groups B2 and D were frequent (36 and $27.8 \%$, respectively) among our isolates; this was expected since virulent extra-intestinal strains belong mainly to these two groups. Extra-intestinal strains possess traits that allow it to invade, colonize, and induce disease in bodily sites outside of the gastrointestinal tract.

Among the studied UPEC strains from Mexico City, a high incidence of antibiotic resistance was determined; in fact, the resistance prevalence observed is among the highest described in the literature [20,4042]. In this study, $83.7 \%$ of the isolates were resistant to ampicillin; and $63.2 \%$ to carbenicillin. These were followed by the quinolone/fluoroquinolone family (CIP, NA, NOR, and OFX) to which 55.5-60.6\% of the isolates were resistant. Finally, resistance to TMP/SMX was $56.4 \%$. These results show that UPEC strains in Mexico City have become sufficiently resistant to treatment with penicillins, fluoroquinolones, and TMP/SMX, as to render their use contraindicated. Other national studies have also shown increasing uropathogenic resistance rates $[18,19]$.

Fluoroquinolone, TMP/SMX, or nitrofurantoin are normally recommended for empirical treatment of uncomplicated UTIs $[43,44]$. However, we found high levels of resistance to fluoroquinolone and TMP/SMX (55.5-60.6\% and 56.2\% resistance, respectively), and worldwide studies indicate the emergence of high levels of fluoroquinolone and TMP/SMX resistance in a significant percentage ( $>20 \%$ and $20-50 \%$, respectively) of community-acquired $E$. coli UTI isolates [38,40,41]. In a recent survey in Mexico, UPEC strains caused growing concern because all three first-choice drugs showed high-resistance prevalence; $74 \%$ of the isolates were resistant to ampicillin, $60.1 \%$ to co-trimoxazole, and $32.6 \%$, to ciprofloxacin $[18,20]$. These findings indicate that initial empirical treatment with ampicillin, fluoroquinolone, and TMP/SMX is no longer appropriate in Mexico City.

Nitrofurantoin was considered the most effective of the drugs that can be orally administered; it represents an alternative for empiric oral therapy of uncomplicated cystitis and is recommended by the 
Infectious Disease Society of America (IDSA) [44]. Nitrofurantoin in this study demonstrated excellent activity against our E. coli isolates $(95 \%$ susceptibility); similarly, in the Unites States and Canada, the rate of resistance to nitrofurantoin was $1.1 \%$ among UPEC isolates [45]. However, in a study in Spain, a diminished susceptibility $(71.3 \%)$ was found to nitrofurantoin among clinical isolates of $E$. coli ESBL producers [46].

Absorption of oral nitrofurantoin is $40-50 \%$, and this is enhanced when it is taken with food; serum concentrations are low to undetectable, and urine concentrations are $50-250 \mathrm{mg} / \mathrm{L}$. This drug is not useful for treating kidney infections or for cases with systemic involvement or renal failure [47]. For these reasons, nitrofurantoin is considered to be an alternative, rather than a first-line, therapeutic agent for this clinical syndrome [47].

In this study, approximately $30 \%$ of UPEC isolates, which are exclusively community-acquired and from Mexico City, exhibit Multidrug-resistant (MDR) phenotypes and these could cause serious infections in ambulatory population. Nicolas-Chanoine et al. (2008) reported a robust virulence gene profile of isolates (from international collection) belonging to the E. coli O25:H4-ST131 lineage, implying substantial extraintestinal pathogenic potential [15].

Therefore, it is important to monitor the status of antimicrobial resistance among uropathogens in order to improve treatment recommendations. The spread of the O25-ST131 clone in Mexico should be monitored closely and the pathogenic mechanisms explaining its success should be investigated. Studies such as this are useful in determining any local trends and risk factors for antimicrobial resistance. For example, physicians and other primary care givers can be apprised of the resistance patterns in their regions and treat patients accordingly; in order to prevent the propagation of penicillin, fluoroquinolones, and TMP/SMX resistance traits, it is no longer advisable to use these antimicrobials for the treatment of UTIs. Finally, in this study, O25-ST131 isolates appeared to be associated with UTI, which highlights the need for robust molecular epidemiological data and risk factor analysis to allow for more accurate understanding of the biology of this organism, so that the future spread of this clone in Mexico and the rest of the world can be monitored.

\section{Acknowledgments}

This study was supported by DGAPA, UNAM, through its PAPIIT Program (No. IN218011-3) and by the Facultad de Medicina,
Departamento de Salud Pública, UNAM, as well as SIP-IPNMexico grant numbers 20091358 and 20101151. GA-O and RMRA are recipients of COFAA-IPN and EDD-IPN fellowships. RH-C was partially funded by CONACyT-SALUD No. 87586 . We thank Luis León Alamilla for technical assistance

\section{References}

1. Foxman B, Brown P (2003) Epidemiology of urinary tract infections: transmission and risk factors, incidence, and costs. Infect Dis Clin North Am 17: 227-241.

2. Griebling TL (2007) Urinary Tract Infections in Women. In: Litwin MS, Saigal CS, editors. Urologic Diseases in America. US Department of Health and Human Services, Public Health Service, National Institutes of Health, National Institute of Diabetes and Digestive and Kidney Diseases. Washington, DC. 587-620.

3. Hooton TM, Stamm WE (1997) Diagnosis and treatment of uncomplicated urinary tract infection. Infect Dis Clin North Am 11: 551-581.

4. Kodner CM, Thomas Gupton EK (2010) Recurrent urinary tract infections in women: diagnosis and management. Am Fam Physician 82: 638-643.

5. Harding GK, Ronald AR (1994) The management of urinary infections; what have we learned in the past decade? Int $\mathbf{J}$ Antimicrob Agents 4: 83-88.

6. Bours PH, Polak R, Hoepelman AI, Delgado E, Jarquin A, Matute AJ (2010) Increasing resistance in communityacquired urinary tract infections in Latin America, five years after the implementation of national therapeutic guidelines. Int J Infect Dis 14: e770-e774.

7. van de Sande-Bruinsma N, Grundmann H, Verloo D, Tiemersma E, Monen J, Goossens H, Ferech M; European Antimicrobial Resistance Surveillance System Group; European Surveillance of Antimicrobial Consumption Project Group (2008) Antimicrobial drug use and resistance in Europe. Emerg Infect Dis 14: 1722-1730.

8. Paterson DL, Bonomo RA (2005) Extended-spectrum betalactamases: a clinical update. Clin Microbiol Rev 18: 657686.

9. Manges AR, Tabor H, Tellis P, Vincent C, Tellier PP (2008) Endemic and epidemic lineages of Escherichia coli that cause urinary tract infections. Emerg Infect Dis 14: 1575-1583.

10. Phillips I, Eykyn S, King A, Gransden WR, Rowe B, Frost JA, Gross RJ (1988) Epidemic multiresistant Escherichia coli infection in West Lambeth Health District. Lancet 1: 10381041.

11. Prats G, Navarro F, Mirelis B, Dalmau D, Margall N, Coll P, Stell A, Johnson JR (2000) Escherichia coli serotype O15:K52:H1 as a uropathogenic clone. J Clin Microbiol 38: 201-209.

12. Whittam TS, Ochman H, Selander RK (1983) Multilocus genetic structure in natural populations of Escherichia coli. Proc Natl Acad Sci U S A 80: 1751-1755.

13. Clermont O, Bonacorsi S, Bingen E (2000) Rapid and simple determination of the Escherichia coli phylogenetic group. Appl Environ Microbiol 66: 4555-4558.

14. Johnson JR, Kuskowski MA, O'Bryan TT, Maslow JN (2002) Epidemiological correlates of virulence genotype and phylogenetic background among Escherichia coli blood isolates from adults with diverse-source bacteremia. J Infect Dis 185: 1439-1447.

15. Nicholas-Chanoine $\mathrm{MH}$, Blanco J, Leflon-Guibout V, Demarty R, Alonso MP, Caniça MM, Park YJ, Lavigne JP, 
Pitout J, Johnson JR (2008) Intercontinental emergence of Escherichia coli clone O25:H4-ST131 producing CTX-M-15. J Antimicrob Chemother 61: 273-281.

16. Coque TM, Novais A, Carattoli A, Poirel L, Pitout J, Peixe L, Baquero F, Cantón R, Nordmann P (2008) Dissemination of clonally related Escherichia coli strains expressing extendedspectrum beta-lactamase CTX-M-15. Emerg Infect Dis 14: 195-200.

17. Johnson JR, Johnston B, Clabots C, Kuskowski Ma, Castanheira M (2010) Escherichia coli sequence type ST131 as the major cause of serious multidrug-resistant E. coli infections in the United States. Clin Infect Dis 51: 286-294.

18. Arredondo-García JL, Amábile-Cuevas CF (2008) High resistance prevalence towards ampicillin, co-trimoxazole and ciprofloxacin, among uropathogenic Escherichia coli isolates in Mexico City. J Infect Dev Ctries 2: 350-353.

19. Guajardo-Lara CE, Gonzáles-Martínez PM, Ayala-Gaytán JJ (2009) Resistencia antimicrobiana en la infección urinaria por Escherichia coli adquirida en la comunidad. ¿Cuál antibiótico voy a usar? Salud Publica Mex 51: 155-158.

20. Amábile-Cuevas C (2010) Antibiotic resistance in Mexico: a brief overview of the current status and its causes. J Infect Dev Ctries 4: 126-131.

21. Wilson ML, Gaido L (2004) Laboratory diagnosis of urinary tract infections in adult patients. Clin Infect Dis 38: 11501158.

22. Carridge JE, Johnson JR, Pezzlo MT (1988) Laboratory diagnosis of urinary tract infections. In: Weissfeld AS, editor. Cumitech 2B. Washington: ASM Press. p. 2-19.

23. Ørskov F, Ørskov I (1984) Serotyping of Escherichia coli. In: Methods in Microbiology 14: 43-112. Edited by T. Bergan. London: Academic Press.

24. Ewing WH. (1986) Edwards and Ewing's Identification of Enterobacteriaceae. New York: Elsevier.

25. Scheutz F, Cheasty T, Woodward, Smith HR (2004). Designation of $\mathrm{O} 174$ and $\mathrm{O} 175$ to temporary O groups OX3 and $\mathrm{OX} 7$, and six new E. coli $\mathrm{O}$ groups that include verocytotoxin producing E. coli (VTEC): O176, O177, O178, O179, O180 and O181. APMIS 112: 569-584.

26. CLSI. (2010) Antimicrobial Susceptibility Testing: Twentieth Informational Supplement. CLSI M100-S20-U. Wayne, PA: Clinical and Laboratory Standards Institute.

27. Clermont O, Dhanji H, Upton M, Gibreel T, Fox A, Boyd D, Mulvey MR, Nordmann P, Ruppé E, Sarthou JL, Frank T, Vimont S, Arlet G, Branger C, Woodford N, Denamur E (2009) Rapid detection of the O25b-ST131 clone of Escherichia coli encompassing the CTX-M-15-producing strains. J Antimicrob Chemother.64: 274-277.

28. Lau SH, Reddy S, Cheesbrough J, Bolton FJ, Willshaw G, Cheasty T, Fox AJ, Upton M (2008) Major uropathogenic Escherichia coli strain isolated in the northwest of England identified by multilocus sequence typing. J Clin Microbiol 46: 1076-1080.

29. Peirano G, Pitout JD (2010) Molecular epidemiology of Escherichia coli producing CTX-M beta-lactamases: the worldwide emergence of clone ST131 O25:H4. Int J Antimicrob Agents 35: 316-321.

30. Kaper JB, Nataro JP, Mobley HLT (2004) Pathogenic Escherichia coli. Nat Rev Microbiol 2: 123-14029.

31. Johnson JR (1991) Virulence factors in Escherichia coli urinary tract infection. Clin Microbiol Rev 4: 80-128.

32. Mitsuda T, Muto T, Yamada M, Kobayashi N, Toba M, Aihara Y, Ito A, Yokota S (1998) Epidemiological study of a food-borne outbreak of enterotoxigenic Escherichia coli O25:NM by pulsed-field gel electrophoresis and randomly amplified polymorphic DNA analysis. J Clin Microbiol 36: 652-656.

33. Ansaruzzaman M, Bhuiyan NA, Begum YA, Kühn I,Nair GB, Sack DA, Svennerholm AM, Qadri F (2007) Characterization of enterotoxigenic Escherichia coli from diarrhoeal patients in Bangladesh using phenotyping and genetic profiling. J Med Microbiol 56: 217-222.

34. Deetz TR, Evans DJ, Evans DG, DuPont HL (1979) Serologic responses to somatic $\mathrm{O}$ and colonization-factor antigens of enterotoxigenic Escherichia coli in travellers. J Infect Dis 140: 114-118.

35. Picard B, Sevali J, Gouriou S, Duriez P, Brahimi N, Bingen E, Elion J, Denamur E (1999) The link between phylogeny and virulence in Escherichia coli extraintestinal infection. Infect Immun 67: 546-553.

36. Johnson JR, Kuskowski MA, Gajewski A, Sahm DF, Karlowsky JA (2004) Virulence characteristics and phylogenetic background of multidrug-resistant and antimicrobial-susceptible clinical isolates of Escherichia coli from across the United States, 2000-2001. J Infect Dis 15: 1739-1744.

37. Cherifi A, Contrepois M, Picard B, Goullet P, de Rycke J, Fairbrother J, Barnouin J (1990) Factors and markers of virulence in Escherichia coli from human septicemia. FEMS Microbiol Let 70: 279-283.

38. Cagnacci S, Gualco L, Debbia E, Schito GC, Marchese A (2008) European emergence of ciprofloxacin-resistant Escherichia coli clonal groups O25:H4-ST 131 and O15:K52:H1 causing community-acquired uncomplicated cystitis. J Clin Microbiol 46: 2605-2612.

39. Leflon-Guibout V, Blanco J, Amaqdouf K, Mora A, Guize L, Nicolas-Chanoine MH (2008) Absence of CTX-M enzymes but high prevalence of clones, including clone ST131, among fecal Escherichia coli isolates from healthy subjects living in the area of Paris, France. J Clin Microbiol 46: 3900-3905.

40. Karlowsky JA, Kelly LJ, Thornsberry C, Jones ME, Sahm DF (2002) Trends in antimicrobial resistance among urinary tract infection isolates of Escherichia coli from female outpatients in the United States. Antimicrob Agents Chemother 46: 25402545.

41. Vasquez Y, Lee Hand W (2004) Antibiotic susceptibility patterns of community-acquired urinary tract infection isolates from female patients on the US (Texas)-Mexico border. J Appl Res 4: 321-326.

42. Gordon KA, Jones RN; SENTRY Participant Groups (Europe, Latin America, North America) (2003) Susceptibility patterns of orally administered antimicrobials among urinary tract infection pathogens from hospitalized patients in North America: comparison report to Europe and Latin America. Results from the SENTRY Antimicrobial Surveillance Program (2000). Diagn Microbiol Infect Dis 45: 295-301.

43. Echols RM, Tosiello RL, Haverstock DC, Tice AD (1999) Demographic, clinical, and treatment parameters influencing the outcome of acute cystitis. Clin Infect Dis 29:113-119.

44. Warren JW, Abrutyn E, Hebel JR, Johnson JR, Schaeffer AJ, Stamm WE (1999) Guidelines for antimicrobial treatment of uncomplicated acute bacterial cystitis and acute pyelonephritis in women. Infectious Diseases Society of America (IDSA). Clin Infect Dis 29: 745-758.

45. Zhanel GG, Hisanaga TL, Laing NM, DeCorby MR, Nichol KA, Weshnoweski B, Johnson J, Noreddin A, Low DE, 
Karlowsky JA; for the NAUTICA Group, Hoban DJ (2006) Antibiotic resistance in Escherichia coli outpatient urinary isolates: final results from the North American Urinary Tract Infection Collaborative Alliance (NAUTICA). Int $\mathbf{J}$ Antimicrob Agents 27: 468-475.

46. Puerto AS, Fernandez JG, del Castillo Jde D, Pino MJ, Angulo JP (2006) In vitro activity of $\beta$-lactam and non- $\beta$ lactam antibiotics in extended-spectrum $\beta$-lactamaseproducing clinical isolates of Escherichia coli. Diagn Microbiol Infect Dis 54: 135-139.

47. Garau J (2008) Other antimicrobials of interest in the era of extended-spectrum B-lactamases: fosfomycin, nitrofurantoin and tigecycline. Clin Microbiol Infect 14: 198-202.

\section{Corresponding author}

Dr. H. Angel Manjarrez-Hernandez

Laboratory of Bacterial Pathogenesis

Departamento de Salud Publica, Facultad de Medicina,

Universidad Nacional Autonoma de México, (UNAM).

Ciudad Universitaria, 04510 Mexico D. F. , Mexico.

Tel. (52-55) 56220831

hangel@unam.mx

Conflict of interests: No conflict of interests is declared. 